\title{
A INCLUSÃO DO ALUNO COM TRANSTORNO DO ESPECTRO AUTISTA NA SALA DE AULA
}

\author{
LA INCLUSIÓN DEL ESTUDIANTE CON EL TRASTORNO DEL ESPECTRO \\ AUTISTA EN EL AULA
}

\author{
THE INCLUSION OF THE STUDENT WITH AUTISTIC SPECTRUM DISORDER IN \\ THE CLASSROOM
}

\author{
Solange Aparecida de Souza MONTEIRO ${ }^{1}$ \\ Paulo Rennes Marçal RIBEIRO²
}

RESUMO: A inclusão educacional escolar de crianças e jovens com Transtornos do Espectro Autista (TEA), vem se mostrando um desafio a todos os envolvidos no processo educativo, nos dias atuais e tem sido meta para as políticas públicas educacionais. A partir desse ensaio teórico, o objetivo deste artigo, é descrever o movimento necessário para a inclusão do aluno com transtorno do espectro autista (TEA) na sala de aula, por meio da caracterização do sujeito, a partir de uma breve análise da legislação, com vistas a contribuir para o debate sobre a educação inclusiva dentro do modelo educacional atual e a defesa da garantia da participação de todos nas experiências educacionais, partilhando os mesmos espaços, vivendo as mesmas experiências e relações sociais sem preconceito de qualquer ordem, motivado pela diferença.

PALAVRAS-CHAVE: Transtorno do espectro autista. Educação inclusiva. Políticas públicas.

RESUMEN: La inclusión educativa de niños y jóvenes con trastornos del espectro autista (TEA) ha sido un desafío para todos los involucrados en el proceso educativo, hoy en día y ha sido el objetivo de las políticas públicas educativas. A partir de este ensayo teórico, el objetivo de este artículo es describir el movimiento necesario para la inclusión del estudiante con el trastorno del espectro autista (TEA) en el aula, a través de la caracterización del tema, a partir de un breve análisis de la legislación, con miras a Contribuir al debate sobre la educación inclusiva dentro del modelo educativo actual y defender la garantía de la participación de todos en las experiencias educativas, compartiendo los mismos espacios, viviendo las mismas experiencias y relaciones sociales sin prejuicios de cualquier orden, motivado por la diferencia.

PALABRAS CLAVE: Trastorno del espectro autista. Educación inclusiva. Política pública.

${ }^{1}$ Instituto Federal de São Paulo (IFSP), Araraquara - SP - Brasil. Pedadoga. Mestra em Processos de Ensino, Gestão e Inovação pela Universidade de Araraquara - UNIARA (2018). Membro dos núcleos: -Núcleo de Gêneros e Sexualidade do IFSP (NUGS); Núcleo de Apoio às Pessoas com Necessidades Educacionais Específicas (NAPNE). ORCID: <http://orcid.org/0000-0002-1640-0266>. E-mail: solmonteiro@ifsp.edu.br ${ }^{2}$ Universidade Estadual Paulista (UNESP), Araraquara - SP - Brasil. Docente do PPG em Educação Escolar e do PPG Educação Sexual. Professor Associado (MS-5), no Departamento de Psicologia da Educação. LivreDocente em Sexologia e Educação Sexual. ORCID: <http://orcid.org/0000-0002-1552-5702>. E-mail: paulo.rennes@unesp.br 
ABSTRACT: The educational inclusion of children and young people with autism spectrum disorders (ASD) has been a challenge for all those involved in the educational process, nowadays and has been the goal for educational public policies. From this theoretical essay, the objective of this article is to describe the necessary movement for the inclusion of the student with Autism spectrum disorder (ASD) in the classroom, through the characterization of the subject, from a brief analysis of the legislation, with a view to Contribute to the debate on inclusive education within the current educational model and to defend the guarantee of the participation of all in educational experiences, sharing the same spaces, living the same experiences and social relations without prejudice of any order, motivated by the difference.

KEYWORDS: Autistic Spectrum disorder. Inclusive education. Public policy.

\section{Introdução}

O apoio em informações de estudiosos e cientistas para discutir a inclusão, investiu-se ao cumprimento das leis, quais foram as mais relevantes para o grupo da educação especial, em particular aos indivíduos com transtorno do espectro autista (TEA), bem como foi expresso o movimento da inclusão na escola, mostrando o surgimento da diversidade desses alunos nas salas de aula comum.

Frente a esse contexto e ciente das dificuldades que o aluno com TEA enfrenta, será destacada neste artigo, a necessidade de sua inclusão efetiva mediante trabalho conjunto de toda a equipe pedagógica para aceitação pela turma e desenvolvimento de suas capacidades, objetivando o seu melhor aproveitamento sociocognitivo. Ao comentar sobre a aprendizagem do aluno autista, também serão destacadas as barreiras que os educadores encaram ao se deparar com alunos com necessidades especiais nas salas de aula comum. Portanto, será descrito o movimento de inclusão nas instituições de ensino, bem como a reestruturação do modo de ensinar para melhor atender o grupo da educação especial. A escola é um dos principais ambientes para o processo de inclusão social.

A mudança de atitude e formação de novos valores humanos é fundamental para uma nova concepção acerca dos alunos com necessidades educativas especiais em particular os autistas, para sabermos como trabalhar de maneira eficaz com esses alunos. Torna-se importante um trabalho em conjunto da professora da sala, com a educadora especial e também com outros profissionais, para assim poder colocar em prática atividades apropriadas que possam melhorar o desenvolvimento social, intelectual e afetivo do aluno com autismo, a defesa de seu direito a educação compartilhada com os demais estudantes em contexto do ensino regular, o que desafia a escola a repensar seu espaço e construir novas lógicas de ensino. 
O paradigma educacional hoje estabelecido nos faz pensar a inclusão de alunos com necessidades educacionais especiais na escola regular como um processo de autonomia no qual todos os estudantes devem conviver e se relacionar socialmente com seus pares para conquistar a autonomia e sua independência.

Um primeiro movimento foi fundamental para a difusão dessa ideia de uma sociedade inclusiva. No ano de 1990, a Organização das Nações Unidas (ONU) utilizou pela primeira vez a expressão "sociedade para todos", sendo registrada na Resolução ONU 45/91, de 14 de dezembro de 1990. E seus documentos constantemente recordavam sobre a meta para a criação de uma sociedade inclusiva no prazo de 20 anos (1991-2010).

Constitui-se, a partir disso, o direito de qualquer pessoa participar de todos os espaços sociais, principalmente, quando se trata da educação, direito básico e fundamental para participação igualitária nos diversos contextos sociais. O direito à educação, Art. 205, é um direito fundamental garantido pela Constituição Federal de 1988 (BRASIL, 1988,) para garantir pelo exercício da cidadania e concretização do respeito à dignidade humana.

Assim, é dever do Estado a garantia desse direito e sua proteção contra qualquer forma de discriminação. Isso o obriga a editar normas para resguardar a observância a esse direito tão fundamental, mas também obriga o Estado a cumprir função de fiscalizar o cumprimento desse direito. O artigo 208 da Constituição Federal em seu inciso III, ainda dispõe que o dever do Estado com a Educação é efetivado mediante a garantia de " [...] atendimento educacional especializado aos portadores de deficiência, preferencialmente na rede regular de ensino" (BRASIL, 1988).

A escola, sob a égide de referências legais, passou a caminhar para garantir a inclusão do aluno que se encontra em situação de vulnerabilidade, por qualquer fator que a promova, oportunizando o aceso e permanência no contexto escolar, prioritariamente, no ensino regular, sendo assim, num primeiro momento, introduzimos a discussão sobre as definições principais de educação inclusiva e sua evolução considerando os paradigmas educacionais sob uma perspectiva histórica. A partir disso, delineamos alguns aspectos legais da atual política educacional brasileira que tangenciam a educação inclusiva. Em um terceiro momento, tratamos das barreiras e desafios colocados para a escolarização das crianças com TEA. À guisa de conclusão, argumentamos que a inclusão de crianças com TEA na rede regular de ensino significa um passo inicial que abre possibilidades para outras transformações não somente de pensamentos, mas também de atitudes em sociedade. 


\section{Uma educação inclusiva}

A própria definição de inclusão tem como sinônimos a ideia de abranger, integrar, compreender. Não é diferente quando falamos da inclusão de pessoas com deficiência ou outras condições pessoais, sociais e culturais. Dessa forma, é esperado dar ao indivíduo o direito de ter as mesmas experiências, aceitando a diversidade e aprendendo com ela. Compreendemos que esses assuntos devem ser trazidos para dentro da escola, discutidos, debatidos, refletidos, para que convicções baseadas no senso comum a respeito das limitações de pessoas com deficiência sejam quebradas e as ações inclusivas não fiquem apenas na teoria, mas se transformem em prática educativa e social.

Segundo Merieu (2005, p. 44), a escola, como princípio fundamental, deve estar aberta a todos, sem descartar ninguém e compartilhar o ensino com todos sem reservas, a sua abertura não é uma questão de escolha, mas sua própria razão de existir. Diante disso, cria-se a necessidade de a filosofia da inclusão ser interpretada, divulgada e traduzida em ações dentro de sala de aula para produzir a inclusão desejada.

Até a década de 1950 pouco ou quase nada se falava em educação das pessoas com deficiência no Brasil. Autores como Januzzi (2004) estabelecem uma periodização do ensino especial associada a três principais fases. Em uma primeira fase, até o início do século XX, a educação de pessoas com deficiência se concentrava no ensino de trabalhos manuais para garantir-lhes a subsistência. Mais adiante, a partir do século XX até a década de 1970, com a primeira Lei de Diretrizes e Bases (LDB), aparecem os primeiros esforços de inserção de alunos com necessidades educacionais especiais na educação regular, mas indicava a necessidade de serviços especiais caso essa inserção não fosse possível. Somente a partir dessa década, a Educação Especial passou a ser discutida entre os governos o que resultou na criação de instituições públicas e privadas, órgãos normativos federais e estaduais e de classes especiais, com caráter mais assistencialista que educacional.

As classes de Ensino Especial, a partir de 1970 sofreram uma avalanche de críticas, autores como Marques (1994) chamavam a atenção para o fato de que estas instituições apesar de bem-intencionadas acabam contribuindo ainda mais para o afastamento do convívio com as demais pessoas não deficientes da sociedade. A educação inclusiva, sobretudo, a partir da década de 80, vem ocupando relevante espaço na sociedade. Atualmente busca-se enfocar a educação sob nova perspectiva social e pedagógica, tendo como objetivo principal educar na e para a diversidade. O objetivo dessa nova perspectiva é possibilitar a todos o 
desenvolvimento em todas as dimensões humanas, independente da condição atual dos sujeitos da educação.

\section{Aspectos legais e diretrizes da atual política educacional}

As leis são criadas para assegurar direitos, mas no cotidiano da sociedade quase nunca são respeitadas e, na maioria das vezes, os direitos das pessoas são ignorados, em especial das pessoas com maior vulnerabilidade social e econômica. Embora o Estatuto da Pessoa com deficiência (BRASIL, 2015), que entrou em vigor em janeiro de 2016, tenha sido um grande avanço como marco legal, muitas vezes para poder exercer o direito é preciso se pôr em luta.

Autores como Meletti e Ribeiro (2014), revelam um cenário na prática que apresenta um descolamento com o cenário desenhado pelas leis. Ao analisar indicadores educacionais sobre a educação especial no Brasil com base no Censo da Educação Básica, as autoras concluem que além do baixo número de matrículas que contrasta com a implementação da política de educação inclusiva, essas matrículas ocorrem mais notadamente nas primeiras séries do ensino fundamental, com grande defasagem de idade quando comparados aos demais alunos isso de forma alguma põe em xeque os importantes marcos legais e diretrizes de política, porém tão somente coloca a discussão necessária sobre o quanto das políticas se traduzem de fato no dia a dia da escola e dos alunos.

Como destacamos, a partir da década de 1970 novas políticas públicas na educação inclusiva começam a ser delineadas. Enquanto no Brasil esse processo se inaugura a partir da Constituição Federal de 1988 (BRASIL, 1988), outro marco importante se refere à Conferência Mundial sobre Necessidades Educativas Especiais, realizada em 1990 na Tailândia, sendo decisiva para impulsionar a Educação Inclusiva em todo o mundo. Essa conferência expos a situação mundial de grandes minorias excluídas e necessidade de se promover a inclusão social através da educação para todos. Estas discussões resultaram na realização de uma conferência de educação em Salamanca na Espanha em 1994, na qual se produziu o documento magno da Educação Inclusiva para mais de oitenta países, inclusive o Brasil.

A Declaração de Salamanca (UNESCO, 1994) é o marco e início do movimento mundial em favor da Educação Inclusiva. Segundo Omote (1999), a grande contribuição da Declaração de Salamanca foi a recomendação dada aos mais de noventa países signatários desta, que em cada um deles fosse adotado o princípio de Educação Inclusiva, em forma de lei 
ou de política, matriculando todas as crianças em escolas regulares, independentemente de suas condições físicas, intelectuais, sociais, emocionais, linguísticas e outras.

Algumas das afirmações e recomendações feitas na Declaração de Salamanca (UNESCO, 1994) foram: toda criança tem direito fundamental à educação, e deve ser dada a oportunidade de atingir e manter o nível adequado de aprendizagem; toda criança possui características, interesses, habilidades e necessidades de aprendizagem que são únicas; sistemas educacionais deveriam ser designados e programas educacionais deveriam ser implementados no sentido de se levar em conta a vasta diversidade de tais características e necessidades; aqueles com necessidades educacionais especiais devem ter acesso à escola regular, que deveria acomodá-los dentro de uma Pedagogia centrada na criança, capaz de satisfazer a tais necessidades; escolas regulares que possuam tal orientação inclusiva constituem os meios mais eficazes de combater atitudes discriminatórias, criando-se comunidades acolhedoras, construindo uma sociedade inclusiva e alcançando educação para todos; além disso, tais escolas propõem uma educação efetiva à maioria das crianças e aprimoram a eficiência e, em última instância, o custo da eficácia de todo o sistema educacional.

Para criar uma política de Educação Inclusiva cumprindo assim com compromisso político assumido na referida declaração e para responder as necessidades educacionais de seus alunos/as, o Brasil instituiu a Lei de Diretrizes e Bases da Educação Nacional - LDB 9.394/96, em 20 de dezembro de 1996 (BRASIL, 1996). Em janeiro de 2016 entrou em vigor a Lei Brasileira de Inclusão nº Lei 13.146/2015 (BRASIL, 2015). Também conhecida como Estatuto da Pessoa com Deficiência, essa lei garante direitos à essas pessoas e prevê punições para casos de discriminação.

As inovações trazidas pela nova lei atingiram as áreas de saúde, educação, trabalho, assistência social, esporte, previdência e transporte. Na inclusão escolar, a lei assegurou a oferta de sistema educacional inclusivo em todos os níveis e modalidades de ensino. Estabeleceu ainda a adoção de um projeto pedagógico que institucionalize o atendimento educacional especializado, com fornecimento de profissionais de apoio, além de proibir as escolas particulares de cobrarem valores adicionais por esses serviços.

Ao se tratar sobre autismo, primeiramente deve-se compreender a educação especial como uma modalidade de ensino. Um sistema de educação caracterizado por um público-alvo que necessita de um olhar diferenciado, pois a escola, ao receber os alunos da educação especial, vai precisar reorganizá-la para que todos os alunos, em especial os autistas, tenham sucesso em seu desenvolvimento social, afetivo e cognitivo. 
Nesse sentido, conceitua-se educação especial como um modo de educar diferenciado, a qual tem como objetivo reestruturar o espaço físico e o sistema de ensino. Com esse enfoque, precisam-se apresentar estratégias na prática pedagógica como procedimento de educação, removendo barreiras para a aprendizagem, bem como contribuir para melhorias na qualidade de ensino dos alunos com autismo.

O Governo Federal, por meio do Ministério da Saúde produziu um documento técnico "Diretrizes de Atenção a Habilitação/Reabilitação das Pessoas com Transtorno de Espectro Autista no SUS" que traz importante avanço e reafirma o direito universal de acesso à saúde e indica a importância de ações intersetoriais, articuladas com a Assistência Social e Educação. O MEC na mesma direção, destaca o direito à educação inclusiva e ao Atendimento Educacional especializado (AEE), reafirmando todos os direitos à educação em todos os níveis, etapas e modalidades de ensino. Conclui-se que o Brasil, ao ter criado a Lei 12.764/12 tornando legitimas suas demandas, nas perspectivas de igualdade de oportunidades.

Para a inclusão da pessoa com TEA, de acordo com o que se expressa legalmente a Lei ${ }^{\circ}$ 12.764, de 27 de dezembro de 2012, que Institui a Política Nacional de Proteção dos Direitos da Pessoa com TEA, reafirmando o ideário inclusivo, já presente em outros documentos. Confirma por considerar que a pessoa com TEA, para todos os efeitos legais, é considerada pessoa com deficiência, sendo garantido o direito de estudar em escolas regulares e "[...] direito a acompanhante especializado" (BRASIL, 2012.

A lei elimina toda e qualquer forma de discriminação e reafirma todos os direitos de cidadania e viabilizar direitos a um diagnóstico precoce, terapias, medicamentos e tratamentos; acesso à educação, proteção social.

Conforme as orientações da LDB - Lei n 9.394/96 (BRASIL, 1996), em seu art. 59, está descrito que
Art. 59. Os sistemas de ensino assegurarão aos educandos com deficiência, transtornos globais do desenvolvimento e altas habilidades ou superdotação: I - currículos, métodos, técnicas, recursos educativos e organização específicos, para atender às suas necessidades; [...] III - professores com especialização adequada em nível médio ou superior, para atendimento especializado, bem como professores do ensino regular capacitados para a integração desses educandos nas classes comuns.

Dessa maneira, como prevê o art. $7^{\circ}$ da Lei $n^{\circ} 12.764 / 12$, para o aluno com TEA é garantida a escolarização, sendo que “[...] o gestor escolar, ou a autoridade competente que recusar a matrícula de aluno com transtorno do espectro autista, ou qualquer outro tipo de deficiência, será punido com multa de 3 (três) a 20 (vinte) salários mínimos”. Dessa forma 
vislumbra-se que o aluno com TEA tem o direito a acesso, permanência e sucesso na escolarização. Prevendo a garantia desse direito, na Constituição Federal, preconiza-se,

Art. 205. A educação, direito de todos e dever do Estado e da família, será promovida e incentivada com a colaboração da sociedade, visando ao pleno desenvolvimento da pessoa, seu preparo para o exercício da cidadania e sua qualificação para o trabalho. Art. 206. O ensino será ministrado com base nos seguintes princípios: I - igualdade de condições para o acesso e permanência na escola; Art. 208. O dever do Estado com a Educação será efetivado mediante a garantia de: III - atendimento educacional especializado aos portadores de deficiência, preferencialmente na rede regular de ensino. (BRASIL, 1988).

Percebe-se que o arcabouço legal para a escolarização do aluno com TEA é bastante significativo, priorizando um campo institucional e educativo que desenvolva a autonomia do sujeito, viabilizando sua interação e socialização nas mais variadas instâncias da sociedade.

A respeito dos direitos do público-alvo da educação especial, pode-se salientar a Política Nacional de Educação Especial na Perspectiva da Educação Inclusiva (BRASIL, 2008), que tem como objetivo garantir educação de qualidade a todos os alunos com deficiência, incluindo alunos com transtornos globais de desenvolvimento e altas habilidades/superdotação garantindo a eles um sistema de ensino que garante os seguintes termos: acesso ao ensino regular, com participação, aprendizagem e continuidade nos níveis mais elevados do ensino; transversalidade da modalidade de educação especial desde a educação infantil até a educação superior; oferta do atendimento educacional especializado; formação de professores para o atendimento educacional especializado e demais profissionais da educação para a inclusão; participação da família e da comunidade; acessibilidade arquitetônica, nos transportes, nos mobiliários, nas comunicações e informação; e articulação intersetorial na implementação das políticas públicas (BRASIL, 2008, p. 14).

São considerados alunos com deficiência àqueles que têm impedimentos de longo prazo, de natureza física, mental, intelectual ou sensorial, que em interação com diversas barreiras podem ter restringida sua participação plena e efetiva na escola e na sociedade. Os alunos com transtornos globais do desenvolvimento são aqueles que apresentam alterações qualitativas das interações sociais recíprocas e na comunicação, um repertório de interesses e atividades restrito, estereotipado e repetitivo. Incluem-se nesse grupo alunos com autismo, síndromes do espectro do autismo e psicose infantil (BRASIL, 2008, p. 15).

\section{O direito do aluno com TEA e sua escolarização}


Crianças com TEA foram vítimas de preconceitos e ideias estereotipadas quanto à sua capacidade. Mais que outras, essas crianças necessitam do convívio e de trocas com pares de sua idade. As atividades motoras, de socialização e linguagem são de grande contribuição para seu desenvolvimento, principalmente linguístico e postural. A inclusão deve ocorrer o mais cedo possível na Educação Infantil, por ter seu trabalho pedagógico voltado aos aspectos do desenvolvimento evolutivo.

De acordo com os teóricos Gauderer, (1987) e Kanner (1943) o termo autismo significa "[...] voltado para si mesmo", indica isolamento social e foi introduzido na psiquiatria em 1906 por Plouller Kanner (1943) reformulou o termo para "distúrbio autístico do contato afetivo".

Kanner detectou duas condições básicas para o autismo: o isolamento e a imutabilidade. Para ele, o autismo pertencia, então, a um grupo de transtornos do neurodesenvolvimento denominados Transtornos Globais do Desenvolvimento (TGDs), Transtornos Invasivos do Desenvolvimento (TIDs) e, atualmente, Transtorno do Espectro do Autismo (TEA). Portanto, atualmente, de acordo com o DSM-5 (AMERICAN PSYCHIATRIC ASSOCIATION, 2013), o diagnóstico de TEA é baseado em duas áreas: (i) prejuízo persistente na interação e na comunicação social e (ii) padrões restritos e repetitivos de comportamento, interesses ou atividades.

Além desses, a inclusão desde a Educação Infantil proporciona outros benefícios, como lembra Mills citado em Schwartzman (1999, p. 23): um dos grandes objetivos da educação infantil é fazer com que a criança seja mais autônoma na sala de aula. Adquirir autonomia é interiorizar regras da vida social para que se possa conduzir sem incomodar o restante do grupo. E essa adequação social é condição sine qua non para que seja integrada.

Os estudantes com TEA podem alcançar elevado nível de aprendizagem, ter uma profissão, dependendo quase exclusivamente das condições pessoais, da qualidade dos estímulos recebidos no meio familiar e social e ainda dos investimentos pedagógicos, de uma educação estimuladora de qualidade e, do quanto se acredita que ele é capaz. Nesse processo, a Educação Especial pode ser determinante no processo de estimulação inicial e cabe ao professor trabalhar suas crianças desenvolvendo nestas capacidades de praticarem atividades diárias, participar das atividades familiares, desenvolver seu direito de cidadania e até mesmo desenvolver uma atividade profissional.

Embora essas crianças apresentem dificuldades na compreensão de metáforas e duplos sentidos (interpretação literal das frases), evitam contato visual, estresse na mudança de rotina, empecilho em interpretar sinais (expressões faciais, expressões verbais), ecolalia (repetições de palavras ou frases), comportamentos motores repetitivos (pular, balançar, fazer 
movimentos com os dedos e/ou mãos, bater palmas, etc.), dentre outras, são capazes de aprender a seu tempo, conforme seu ritmo e alcançar nível de desenvolvimento diferenciado de acordo com suas potencialidades. Necessitam apenas de maior atenção e condições favoráveis de ensino. Importante salientar que independentemente de se ter ou não uma deficiência, todas as crianças passam pelos mesmos estágios de desenvolvimento. As com deficiência, principalmente intelectual, experimentam um processo mais demorado, lembra Schwartzman (1999) ao mencionar

O fato de a criança não ter desenvolvido uma habilidade ou demonstrar conduta imatura em determinada idade, comparativamente a outras com idêntica condição genética, não significa impedimento para adquiri-la mais tarde, pois é possível que madure lentamente (SCHWARTZMAN, 1999, p. 246).

A escola regular deve ser o lugar de aprendizagem, convívio, integração e participação do aluno com TEA. Estudiosos como Claudia Werneck (1997, p. 56), ressaltam que é preciso avançar neste processo e afirma que evoluir é perceber que incluir não é tratar igual, pois as pessoas são diferentes. Alunos diferentes terão oportunidades diferentes, para que o ensino alcance os mesmos objetivos. Nesse sentido, incluir é abandonar estereótipos.

Muitos professores (as) por falta de formação e informação, num primeiro momento podem pensar que a inclusão da criança com TEA não será possível e que isso poderá prejudicar a aprendizagem dos alunos. Neste caso, destaca-se a importância de relatos de experiências de pedagogos com núcleos dedicados à educação inclusiva de alunos com TEA, na desconstrução dessas crenças (ONOFRE, 2017). O preconceito é gerado por falta de informação e até mesmo por insegurança, e por esse motivo o processo de inclusão será tão mais natural se tiver início ainda na infância.

A participação da família no processo de escolarização destas crianças é de fundamental importância, visto que nos relatos de experiências como de Onofre (2017) destaca-se a importância do envolvimento da comunidade e do apoio aos familiares na difusão de novos paradigmas educacionais relacionados à educação inclusiva. Nesse sentido, consideramos que a inclusão das crianças com TEA e a inclusão como um todo ainda enfrentam inúmeros paradigmas dentro do ambiente escolar, para que realmente a inclusão aconteça na prática é necessário um repensar de todos os segmentos seja escolar ou familiar só através dessa prática e do elo entre esses segmentos que a inclusão realmente acontecerá.

A educação é um direito de todos e negar matrícula em escolas públicas ou particulares é crime, como diz a Lei $\mathrm{n}^{\circ} 7853 / 89$ em seu Artigo $8^{\circ}$, mesmo assim, muitos pais 
ainda encontram dificuldades em matricular seus filhos com deficiência na rede regular de ensino e, quando a matrícula é realizada, nem sempre o ensino ocorre como deveria (BRASIL, 1989).

O sistema educacional brasileiro enfrenta o desafio de alcançar a educação que contemple a diversidade da condição humana. A inclusão escolar apresenta uma grande distância entre o ideal, garantido legalmente para uma educação de qualidade para todos, e o real que são as condições atuais do sistema escolar (SILVA, 2009).

Para Elias (2018), o diagnóstico é baseado em duas áreas: (i) prejuízo persistente na interação e na comunicação social e (ii) padrões restritos e repetitivos de comportamento, interesses ou atividades. Essas características têm base tanto neurológica quanto ambiental, e as modificações ambientais estão dentro das possibilidades mais imediatas em contexto educacional.

Cada aluno autista é diferente do outro e que possui diferentes dificuldades e capacidades. Assim, é fundamental o professor incluir novas alternativas de ensinar esses alunos, trazendo práticas pedagógicas que consiga fazê-los socializar e interagir a partir de trocas de experiências com seus pares. Proporcionando, assim, um trabalho de desenvolvimento social, efetivo e intelectual do aluno com autismo, além do trabalho interativo de inclusão efetiva.

A prática da educação inclusiva e sua concretização está nas mãos dos profissionais da educação e nem sempre a legislação considera esse importante variável. Segundo Correia (1999), espera-se do professor do ensino regular que utilize estratégias diferenciadas para o ensino individualizado, mantenha uma metodologia eficaz para o resto do grupo e colabore na integração social da classe, mas sem a formação adequada e sem conhecer a natureza dos problemas de cada aluno e suas implicações no processo educativo, o professor acaba não podendo prestar o apoio adequado.

Para Elias (2018), cada pessoa com TEA é única, em função da sua própria história de vida e dos meios físicos e sociais onde está inserida, e, nesse sentido, não há uma forma universal e totalmente efetiva para todas as pessoas com TEA. É preciso estudar e entender cada caso e planejar tanto as modificações ambientais quanto o processo educacional de forma a atender as suas necessidades, considerando as suas competências.

De acordo com Bakthin (2010, p. 98),

O simples fato de que eu, a partir do meu lugar único no existir, veja, conheça um outro, pense nele, não o esqueça, o fato de que também para mim ele existe - tudo isso é alguma coisa que somente eu, único, em todo o existir, em um dado momento, posso fazer por ele: um ato vivido real em 
mim que completa a sua existência, absolutamente profícuo e novo, e que encontra em mim somente a sua possibilidade.

Sendo assim, diante do aluno com autismo buscamos a formação humana e que este processo se dá na escola. Todos podem aprender e a escola e seus profissionais, essencialmente o professor, não podem abrir mão de sua função/responsabilidade (BAKHTIN, 2010)

Refletir sobre o trabalho pedagógico para os sujeitos com autismo envolve descobrir como tornar acessível o conhecimento por meio da nossa cultura, da nossa história e da nossa experiência humana.

Por isso, na escola, precisamos defender um trabalho educativo que busque tornar o conhecimento mais acessível ao aluno com autismo, que envolva sua participação, na busca de possibilidades de apropriação dos elementos culturais que favoreçam "[...] as possibilidades humanas de aprender, de desenvolver-se, de superar -se" (BARROCO, 2011, p. 170).

\section{Considerações finais}

Em vista do exposto, a inclusão de crianças com TEA na rede regular de ensino significa, em nossa concepção, um passo inicial que abre possibilidades para outras transformações não somente de pensamentos, mas também de atitudes em sociedade.

Superar as barreiras colocados para a escolarização das crianças com TEA, se torna um grande desafio, para os que não consideram esses sujeitos como educáveis, para os que insistem em ver somente o autismo com a lente da impossibilidade. ao trazer estratégias eficientes de práticas pedagógicas, diversificação curriculares para o aluno com transtorno do espectro autista, apropriado à grande inconstância encontrada nas pessoas dentro do espectro, a incontestabilidade das estratégias eficazes dependerá de muitos fatores, muitas vezes externos ao contexto educacional. Alguns desses fatores como a idade em que a criança recebe o diagnóstico e tem início a orientação educacional em relação ao que competem a situação de ensino, o rompimento com atitudes inadequadas dificuldade das demandas apresentadas, notadamente na disposição atual do aluno, tendo em vista os efeitos colaterais de medicamentos administrados, dificuldades com o sono, alimentação, desencadeando problemas de concentração e falta de atenção.

A educação em escola regular produz benefícios durante toda a vida dos estudantes com TEA e merece ser amplamente discutida. A discussão a esse respeito ainda carece de 
relatos na literatura sobre boas práticas no contexto da educação inclusiva. Além de transmitir conhecimentos acadêmicos, a escolarização é um passo fundamental no processo de socialização e no desenvolvimento emocional e afetivo. Conviver com pessoas de diferentes origens e formações em uma escola regular e inclusiva pode ajudar ainda mais as pessoas com TEA a desenvolverem todas as suas potencialidades.

Os profissionais da educação têm papel fundamental nesse processo de aprendizado e o professor é continuamente desafiado a responder as novas expectativas projetadas sobre ele com a implantação do modelo inclusivo de educação e de ser professor/humano, torna-se essencial que a base de sua formação seja pautada no ato responsável em seu fazer pedagógico.

Nesse contexto, nota-se que, embora existam professores bem-intencionados e dispostos a repensar as metodologias e o espaço escolar, não podemos dizer que isso seja observado de forma geral. Infelizmente, muito dos profissionais envolvidos no processo educativo ainda não estão predispostos à diversidade, sendo que isso é fator decisivo para remover obstáculos e traçar caminhos concretos para a educação inclusiva.

Contudo, sabemos o quanto é fundamental a inclusão do aluno com TEA na sala de aula para seu avanço no desenvolvimento social, efetivo e cognitivo. Por isso, temos que proporcionar um ambiente escolar que auxilie na integração desse aluno, proporcionando a eles uma ativa participação e sala de aula com os seus pares e assim teremos uma aprendizagem de qualidade a todos os alunos.

Retomando alguns pontos que refletimos ao longo do texto sobre a educação inclusiva do aluno com TEA na sala de aula, conclui-se que as escolas e os velhos paradigmas de educação precisam ser transformados para atender às necessidades individuais de todos os alunos, tenham eles ou não algum tipo de necessidade especial. Se nos detivermos na divisão educacional de "normais" e "deficientes", não conseguiremos romper com paradigmas e fazer a mudança que a inclusão propõe,

Portanto não se trata simplesmente de o aluno com TEA estar inserido no ensino regular, deve-se proporcionar aulas de qualidade e agradáveis e que através da inclusão o aluno se sinta integrado na sala de aula juntamente com os seus pares e professor. Dessa forma o professor em reflexão crítica recria sua própria tarefa, descobrindo novos caminhos, melhorando a qualidade de ensino de forma adequada a situações novas, assegurando a inclusão da criança com TEA. Reconhecer que a diversidade humana faz parte dessa estrutura e que valorizá-la se traduz em lhes conceder o respeito e a oportunidade de fazerem parte vida de todos, sem discriminação de qualquer espécie, é o primeiro passo para a construção de uma 
sociedade mais inclusiva e livre de preconceitos. A capacidade do professor em conviver com os diferentes, superando os preconceitos a partir da sala de aula, a inclusão de crianças com TEA na rede regular de ensino significa um passo inicial que abre possibilidades para outras transformações não somente de pensamentos, mas também de atitudes na sociedade, inclusão não apenas colocar o aluno dentro da sala de aula regular, mas inseri-lo dentro do contexto escolar construindo novos conhecimentos, no sentidos e prazeres.

\section{REFERÊNCIAS}

BAKHTIN, M. Para uma filosofia do ato responsável. Tradução de Valdemir Miotello \& Carlos Alberto Faraco. São Carlos: Pedro \& João, 2010.

BARROCO, S. M. S. Pedagogia histórico-crítica, psicologia histórico-cultural e educação especial: em defesa da pessoa com e sem deficiência. In: MARSIGLIA, A. C. G.(org.) Pedagogia histórico-crítica: 30 anos. Campinas, SP: Autores Associados, 2011. p.169-196

BRASIL. Constituição da República Federativa do Brasil. Brasília: Senado Federal, 1988.

BRASIL. Lei 9.394, de 20 de dezembro de 1996. Estabelece as Diretrizes e Bases da Educação Nacional. Diário Oficial da União, 23 de dezembro de 1996.

BRASIL. Lei 12.764, de 27 de dezembro de 2012. Institui a Política Nacional de Proteção dos Direitos da Pessoa com Transtorno do Espectro Autista. Diário Oficial da União, 28 de dezembro de 2012.

BRASIL. Lei $\mathbf{n}^{\mathbf{0}}$ 13.146, de 6 de julho de 2015. Institui a Lei Brasileira de Inclusão da Pessoa com Deficiência (Estatuto da Pessoa com Deficiência). Disponível em: http://www.planalto.gov.br/ccivil_03/_Ato2015-2018/2015/Lei/L13146.htm. Acesso em: 16 dez. 2018.

CORREIA, L. de M. Alunos com necessidades educativas especiais nas classes regulares. Portugal: Porto Editora, 1999. (Colecção Educação Especial, 1).

ELIAS, N. C. Transtorno do espectro do autismo e intervenções comportamentais. In: GOLÇALVES, A. G.; CIA, F.; CAMPOS, J. Ap. de P. P. (Org.). Letramento para o estudante com deficiência. 1 ed. São Carlos: EdUFSCar, 2018, v. 1, p. 9-14.

FERREIRA, M. M. Educação inclusiva: Inclusão de crianças com Síndrome de Down no ciclo I do ensino fundamental. Anais... II Encontro Científico e II Simpósio de Educação, Lins, $2009 . \quad$ Disponível em: http://www.unisalesiano.edu.br/encontro2009/trabalho/aceitos/cc31441044850.pdf. Acesso em: 13 dez 2018.

JANNUZZI, G. de M. A educação do deficiente no Brasil: dos primórdios ao início do século XXI. Campinas: Autores Associados, 2004. 
MARQUES, C. A. Para uma Filosofia da deficiência: aspectos da pessoa portadora de deficiência. Juiz de Fora: UFRJ, 1994.

MEIRIEU, P. O cotidiano da escola e da sala de aula o fazer e o compreender. Porto Alegre: Artmed, 2005.

MELETTI, S. M. F.; RIBEIRO, K. Indicadores educacionais sobre a educação especial no Brasil. Caderno Cedes, Campinas, v. 34, n. 93, p. 175-189, maio/ago., 2014.

MENDES, E. G. Perspectivas para a construção da escola inclusiva no Brasil. In: PALHARES, M.; MARINS, S. (orgs.) Escola Inclusiva. São Carlos: EdUFSCar, p. 61-85, 2002.

OMOTE, S. Normatização, integração, inclusão. Revista Ponto de Vista. Florianópolis, v. 1, n. 1, jul./dez., 1999.

ONOFRE, J. A. Aprendendo com a educação inclusiva: experiências no núcleo "Aprendendo Down”. Extensão \& Cidadania, Vitória da Conquista, v. 4, n. 7, p. 7-13, jan./jun., 2017.

SILVA, B. K. L. N. Inclusão Escolar de uma Criança com Síndorme de Down. In: IX Congresso Nacional de Educação - EDUCERE, III Encontro Sul Brasileiro de Psicopedagogia. PUCRS, 26 a 29 de outubro de 2009. Disponível em: http://www.pucpr.br/eventos/educere/educere2009/anais/pdf/2465_1462.pdf. Acesso em: 30 abr. 2016.

SCHWARTZMAN, J. S. Síndrome de Down São Paulo: Memnon, 1999.

UNESCO. Declaração de Salamanca e linha de ação sobre necessidades educativas especiais. Brasília: CORDE, 1994.

VOIVODIC, Maria Antonieta. Inclusão escolar de crianças com síndrome de down. Petrópolis: Vozes, 2004.

WERNECK, C. Ninguém mais vai ser bonzinho na sociedade inclusiva. Rio de Janeiro: WVA, 1997.

\section{Como referenciar este artigo}

MONTEIRO, Solange Aparecida de Souza.; RIBEIRO, Paulo Rennes Marçal. A inclusão do aluno com transtorno do espectro autista na sala de aula. Revista on line de Política e Gestão Educacional, Araraquara, v. 22, n. esp. 2, p. 905-919, dez., 2018. ISSN: 1519-9029. DOI: 10.22633/rpge.unesp.v22.nesp2.dez.2018.11991

Submetido em: 30/09/2018

Revisões requeridas: $15 / 10 / 2018$

Aprovado em: 14/11/2018 